\title{
Novel Anti-Cancer Peptides Comprising Three Amino Acids*
}

\author{
Michael Agrez ${ }^{1}$, Madhu Garg ${ }^{2,3}$, Stephen Ackland ${ }^{2,3,4}$ \\ ${ }^{1}$ Division of Surgery, John Hunter Hospital, Newcastle, Australia; ${ }^{2}$ Department of Medical Oncology, Calvary Mater Hospital, \\ Waratah, Australia; ${ }^{3}$ Hunter Medical Research Institute, John Hunter Hospital, Newcastle, Australia; ${ }^{4}$ Faculty of Health, The Univer- \\ sity of Newcastle, Callaghan, Australia. \\ Email: michael.agrez@hnehealth.nsw.gov.au
}

Received May 21 ${ }^{\text {st }}, 2012$; revised June $25^{\text {th }}, 2012$; accepted July $9^{\text {th }}, 2012$

\begin{abstract}
Background: The NPxY motif common to all $\beta$ integrin cytoplasmic domains forms part of a canonical recognition sequence for phosphotyrosine-binding domains which are protein modules present in a wide variety of signaling and cytoskeletal proteins. We have recently reported that a non-naturally occurring peptide, RSKAKNPLYR, derived from the $\beta 6$ integrin cytoplasmic domain inhibits cancer cell growth in vitro and proposed that this may be due, at least in part, to the inhibition of c-Src activity [1]. In the present study we examined the role of the NPLY motif within RSKAKNPLYR in terms of its requirement for inhibition of cancer cell growth. Materials and Methods: The effects of peptide modifications to RSKAKNPLYR on in vitro proliferation of human cancer cell lines (colorectal HT29, prostate DU145, breast MCF-7 and ovarian A2780) were evaluated using the MTT cell growth assay. Passage of peptide across the plasma membrane was assessed by means of confocal microscopy using FITC-labelled peptide. The effect of peptide on kinase activity was assessed in cell-free in vitro kinase assays. Results: The NPLY motif within RSKAKNPLYR was found to be essential for the growth inhibitory effect of this peptide. However, modified forms of this peptide in which all amino acids except the charged residues arginine and lysine were replaced by single non-polar amino acids such as alanine or valine were equally effective at inhibiting cancer cell proliferation. Moreover, these peptides inhibited not only c-Src activity as seen for RSKAKNPLYR but also the activity of members of the PKB/Akt kinase family. Conclusion: Novel decapeptides comprising only three amino acids have anti-cancer effects without the requirement for an integrin-based NPLY motif. These peptides inhibit the activity of not only c-Src but also members of the Akt family of kinases and may be useful as potential anti-cancer agents when used either alone or in combination with compounds previously reported to inhibit c-Src kinase activity.
\end{abstract}

Keywords: Peptides; Cancer Cell Lines; MTT Assay; Kinase Activity; c-Src; Akt

\section{Introduction}

Integrins comprise a family of cell adhesion receptors composed of alpha/beta heterodimeric subunits that provide a functional and structural bridge between the extracellular matrix and intracellular signaling molecules [2]. The importance of integrins as components of extra- and intracellular signaling pathways in cancer is only just emerging. Expression of the $\alpha \mathrm{v} \beta 6$ integrin in ovarian cancers may contribute to the invasive potential of ovarian cancers [3] and in colon cancer it has been identified as an independent prognostic indicator for worse outcome in patients suffering from this disease [4]. We have previously reported that a sequence of 15 amino acids, RSKAKWQTGTNPLYR, located within the cytoplasmic tail of the $\beta 6$ integrin subunit binds to extracellular signal-

\footnotetext{
${ }^{*}$ Conflict of Interest: None.
}

regulated kinase 2 (ERK2) and proposed that this contributes to tumor growth [5]. More recently, we reported that a novel peptide, RSKAKNPLYR, derived from the $\beta 6$ binding sequence inhibits cancer cell growth in vitro and proposed that this may be due, in part at least, to the inhibition of c-Src activity [1].

Notably, within the RSKAKNPLYR sequence there is an NPxY motif common to all beta integrin cytoplasmic domains that forms part of a canonical recognition sequence for phosphotyrosine - binding (PTB) domains which are protein modules present in a wide variety of signaling and cytoskeletal proteins. Accordingly, it has been suggested that phosphorylation of the tyrosine $(\mathrm{Y})$ residue in the NPxY motif may represent a mode of regulating integrin interactions with other proteins at the cytoplasmic face of the plasma membrane [6]. The fundamental role for the highly conserved NPxY motif in regulating in- 
tegrin-mediated function has been emphasized by Filardo and colleagues who showed that the NPxY motif within the $\beta 3$ cytoplasmic tail is essential for $\alpha \mathrm{v} \beta 3$-dependent post-ligand binding events involved in cell migration and the metastatic phenotype of melanoma cells [7].

In the present study we examined the role of the NPLY motif within the $\beta 6$-derived anti-cancer decapeptide, RSKAKNPLYR, in terms of its requirement for inhibition of cancer cell growth. To our surprise, novel small anti-cancer peptides that lacked the NPLY motif were identified comprising only three amino acids, i.e., arginine, lysine and a non-polar amino acid such as alanine or valine. Moreover, these peptides inhibited not only c-Src activity in a manner similar to RSKAKNPLYR but also the activity of members of the PKB/Akt kinase family.

\section{Materials \& Methods}

\subsection{Peptides, Cell Lines and Culture Conditions}

All peptides were synthesized by Auspep, Melbourne, Australia. The peptides were RSKAKNPLYR, RKRK, RKKR, ASAAANPLYA, RSKAKR, RSKAKNPLAR, RSKAKNALYR, RAKAKAAAAR, RAAKAARAAK, KAKAKAAAAK, RARAKAAAAK, RARARAAAAR, RAKARAAAAK, KARARAAAAK, R $\beta$ AK $\beta$ AK $\beta$ A $\beta$ A $\beta$ A $\beta$ AR, RAKAK, RAKAKAAAR, RAKAKAAAAAR, RSKSKSSSSR, RGKGKGGGGR and RVKVKVVVVR. For immune-fluorescent studies an extra lysine residue was coupled to the amino-terminus of RAKAKAAAAR to provide attachment for FITC (designated FITC-K10(4) Ala).

The human colon cancer cell line HT29, an ovarian cancer cell line, A2780, a breast cancer cell line MCF-7 and a prostate cancer cell line DU145 were bought from the American Type Culture Collection (ATCC). The cell lines were cultured at $37^{\circ} \mathrm{C}$, under air containing $5 \% \mathrm{CO}_{2}$ and passaged regularly for optimal growth. Cells were maintained in DMEM medium (HyClone Laboratories, Utah, USA) containing $10 \%$ fetal bovine serum (FBS) (SAFC Biosciences, Kansas, USA). All culture medium preparations were further supplemented with penicillin/streptomycin $(100 \mu \mathrm{g} / \mathrm{ml})$ and glutamine (2 mM) (Gibco, Life Technologies, Australia).

\subsection{In vitro Growth Inhibition MTT Assay}

Cells in logarithmic growth were transferred to 96-well plates (Costar, Corning Incorporated, NY, USA) in 100 $\mu \mathrm{l}$ of serum-containing medium at a density of 4000 cells per well. After 24 hours the previously added serum-containing medium was removed and $200 \mu$ l of serum-free medium with or without peptide added to each of triplicate wells. Drug exposure experiments were carried out on cell lines using varying concentrations of peptides
(50 nM - $100 \mu \mathrm{M}$ ) and cells were exposed to peptides for 72 hours. Growth-inhibitory effects were evaluated using the MTT (3-[4,5-dimethylthiazol-2-yl] 2,5-diphenyl-tetrazolium bromide) cell growth assay and absorbance read at $540 \mathrm{~nm}$. Growth of control cells was exponential during the whole incubation period. Mean surviving fractions \pm SEM values (minimum of 3 separate experiments) were determined for each peptide concentration.

\section{3. c-Src Kinase Activity Assay}

In vitro c-Src kinase activity assays were performed by Upstate Kinase Profiling, Dundee, Scotland according to the manufacturer's instructions. In brief, in a final reaction volume of $25 \mu \mathrm{L}, \mathrm{c}-\mathrm{Src}(5-10 \mathrm{mU})$ was incubated with 8 mM MOPS pH 7.0, 0.2 mM EDTA, $250 \mu \mathrm{M}$ KVEKIGEGTYGVVYK (Cdc2 peptide), $10 \mathrm{mM} \mathrm{Mg}$ Acetate and [Y-33P-ATP] (specific activity approximately 500 $\mathrm{cpm} / \mathrm{pmol}$ ). The reaction was initiated by the addition of the Mg-ATP mix. After incubation for 40 minutes at room temperature, the reaction was stopped by the addition of $5 \mu \mathrm{L}$ of a $3 \%$ phosphoric acid solution. $10 \mu \mathrm{L}$ of the reaction was then spotted onto a P30 filtermat and washed three times for 5 minutes in $75 \mathrm{mM}$ phosphoric acid and once in methanol prior to drying and scintillation counting.

\subsection{PKB (Akt) Kinase Activity Assay}

In vitro $\mathrm{PKB}$ kinase activity assays were performed by Upstate Kinase Profiling, Dundee, Scotland according to the manufacturer's instructions. In final reaction volumes of $25 \mu \mathrm{L}, 5-10 \mathrm{mU}$ of either $\mathrm{PKB} \beta$ (Akt2) or PKB $r$ (Akt3) were incubated with $8 \mathrm{mM}$ MOPS $\mathrm{pH} 7.0,0.2$ mM EDTA, $30 \mu \mathrm{M}$ of GRPRTSSFAEGKK, $10 \mathrm{mM} \mathrm{Mg}$ Acetate and ( $\Upsilon$-33P-ATP) (specific activity approximately $500 \mathrm{cpm} / \mathrm{pmol}$, concentration as required). The reaction was initiated by the addition of the Mg-ATP mix. After incubation for 40 minutes at room temperature the reaction was stopped by the addition of $5 \mu \mathrm{L}$ of a $3 \%$ phosphoric acid solution. $10 \mu \mathrm{L}$ of the reaction mix was then spotted on to P30 filtermat and washed three times for 5 minutes in $75 \mathrm{mM}$ phosphoric acid and once in methanol prior to drying and scintillation counting.

\subsection{Peptide Internalization into Cells}

HT29 cells were seeded into four $35 \mathrm{~mm}$ optically clear cell culture dishes at a density of $1 \times 10^{6}$ cells per dish in $1 \mathrm{~mL}$ of RPMI cell culture medium with supplements (penicillin/streptomycin and glutamine). The following day, media was removed from the four dishes and the adherent cells gently washed twice with $1 \mathrm{~mL}$ PBS followed by addition of $1 \mathrm{~mL}$ of RPMI cell culture medium with supplements minus FBS. FITC compounds (FITC alone and FITC-labelled peptide designated FITC-K10(4) 
Ala (FITC-KRAKAKAAAAR)) were resuspended in DMSO to give a final concentration of $1 \mathrm{mM} .10 \mu \mathrm{L}$ of FITC was added to two dishes and $10 \mu \mathrm{L}$ of FITC-K10(4) Ala was added to the other two dishes to give a final compound concentration of $10 \mu \mathrm{M}$ per dish. The dishes were incubated at $37^{\circ} \mathrm{C}$ for 24 hours.

Confocal microscopy was performed using a Nikon C1Z laser-scanning confocal system equipped with a Nikon E-2000 inverted microscope and three solid laser lines (Sapphire 488 nm, Compass 532 nm, Compass 405 nm). A Nikon $60 \times$ water-immersion lens (NA = 1.2) objective was used. Green fluorescence was excited with Ar 488 $\mathrm{nm}$ laser line and the emission viewed through BA 495 $520 \mathrm{~nm}$ narrow band barrier filter. Nikon C1Z software was used to process the images.

\section{Results}

\subsection{Effect of Peptide Modifications on Cell Proliferation in vitro}

We initially examined the effects of peptide modifications to the $\beta 6$-derived peptide RSKAKNPLYR that included

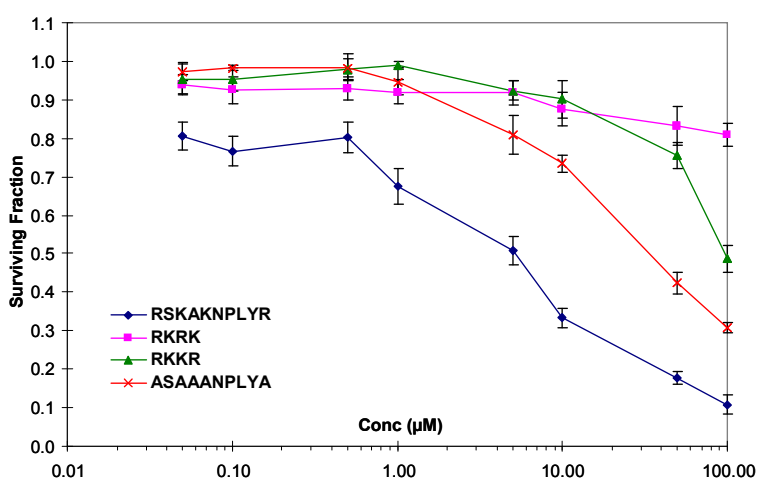

(a)

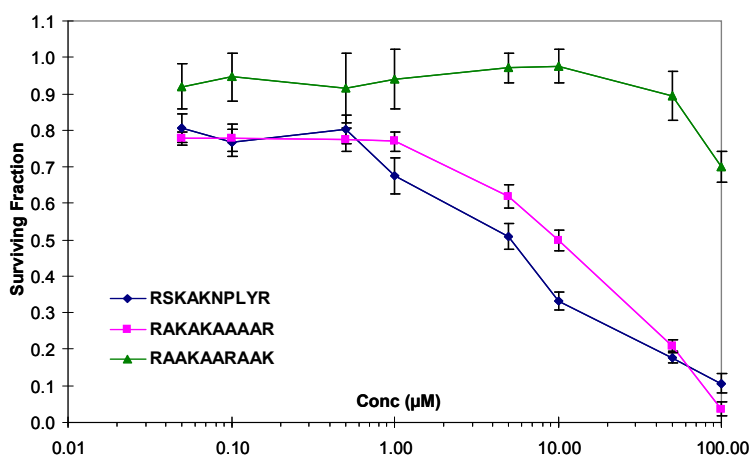

(c) substitution of the charged residues ( $\mathrm{R}$ and $\mathrm{K}$ ) by alanine as well as 4-mer peptides comprising only the charged residues (RKRK and RKKR). As shown in Figure 1(a), both the NPLY motif and the charged residues $\mathrm{R}$ and $\mathrm{K}$ appeared necessary but not sufficient to inhibit proliferation of HT29 cells in vitro to the same degree as seen for the full length $\beta 6$-derived 10 -mer peptide (see Figure 1(a)). Notably, the scrambled version of the 4-mer peptide RKKR (i.e., RKRK) was less effective at inhibiting cell proliferation at the highest peptide concentration of $100 \mu \mathrm{M}$ (Figure 1(a)).

Given the putative importance of the NPxY motif in regulating integrin function we specifically examined the effect of a deletion variant of RSKAKNPLYR that lacked the NPLY sequence (i.e., RSKAKR) on cell prolixferation. As shown in Figure 1(b), RSKAKR failed to inhibit proliferation of HT29 cells even at the highest concentration of $100 \mu \mathrm{M}$. Moreover, substitution of the specific residues proline and tyrosine by alanine within the NPLY motif abrogated the growth inhibitory effect seen in the presence of the parent 10-mer RSKAKNPLYR as shown in Figure 1(b).

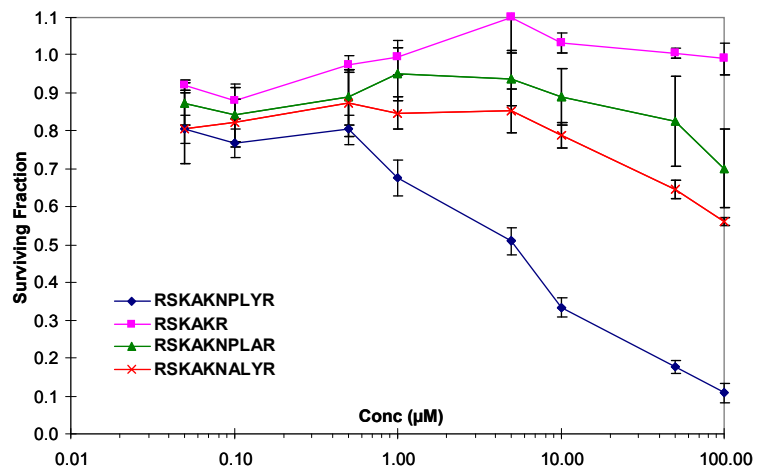

(b)

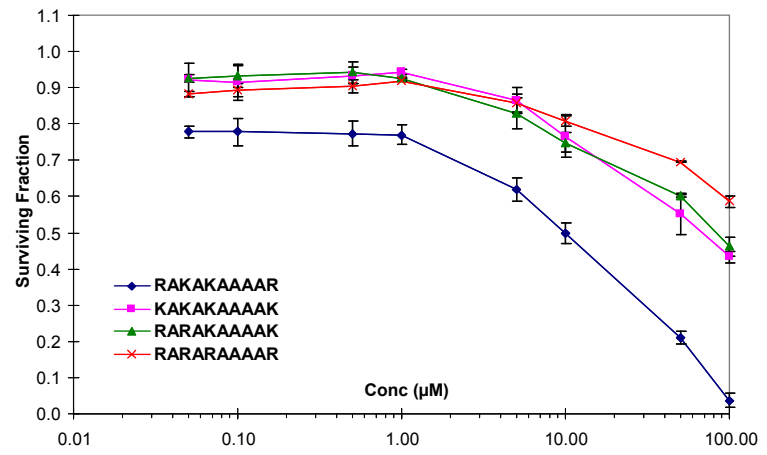

(d)

Figure 1. (a) HT29 colon cancer cells cultured under serum-free conditions and exposed to peptides for 72 hours (RSKAKNPLYR versus RKKR versus ASAAANPLYA versus RKRK); (b) HT29 colon cancer cells cultured under serum-free conditions and exposed to peptides for 72 hours (RSKAKNPLYR versus RSKAKR versus RSKAKNPLAR versus RSKAKNALYR); (c) HT29 colon cancer cells cultured under serum-free conditions and exposed to peptides for 72 hours (RSKAKNPLYR versus RAKAKAAAAR versus RAAKAARAAK scrambled RAKAKAAAAR); (d) HT29 colon cancer cells cultured under serum-free conditions and exposed to peptides for 72 hours (RAKAKAAAAR versus KAKAKAAAAK versus RARAKAAAAK versus RARARAAAAR). All data represent the means \pm SEM of the means for at least three separate experiments. 
To further confirm that the NPLY motif was necessary to inhibit cancer cell growth, all non-charged residues within RSKAKNPLYR were replaced with alanine and the resulting peptide RAKAKAAAAR tested for its effect on proliferation of HT29 cells. Surprisingly, as shown in Figure 1(c), the ability of both peptides to inhibit cell growth was similar whereas a scrambled version of RAKAKAAAAR (i.e., RAAKAARAAK) was ineffective (Figure 1(c)).

The 10-mer peptides derived from the $\beta 2, \beta 3$ and $\beta 5$ integrin cytoplasmic domains (KEKLKNPLFK, RARAKNPLYK and RSRARNPLYR, respectively) share significant homology with the $\beta 6$-derived peptide RSKAKNPLYR and have been shown to inhibit proliferation of colon cancer cells in vitro [8]. We therefore compared the growth inhibitory effect seen for RAKAKAAAAR with 10 -mer peptides in which all but the charged residues of the $\beta 2, \beta 3$ and $\beta 5$-integrin-derived peptides were substituted by alanine (KAKAKAAAAK, RARAKAAAAK and RARARAAAAR, respectively). As shown in Figure 1D, RAKAKAAAAR was more effective at inhibiting proliferation of HT29 cells in vitro than the three alaninesubstituted peptides derived from the $\beta 2, \beta 3$ and $\beta 5$ integrin cytplasmic domains.

In order to determine whether the positions of arginine and lysine within RAKAKAAAAR affected the ability of this peptide to inhibit cancer cell growth, HT29 cells were cultured in the presence of peptides in which the positions of one or both arginine and lysine residues had been inverted (RAKARAAAAK and KARARAAAAK, respectively). As shown in Figure 2(a), this reduced the ability of the peptides to inhibit cell growth. Moreover, conversion of all alanine residues within RAKAKAAAAR to the isomeric form, $\beta$-alanine, similarly reduced the ability of the peptide to inhibit growth of HT29 cells as shown in Figure 2(a).

The specific requirement for four alanine residues within the carboxy-terminal component of RAKAKAAAAR for optimal growth-inhibitory effects is shown in Figure 2(b). As seen in Figure 2(b) shorter variants of RAKAKAAAAR, ie, RAKAK and RAKAKAAAR, had minimal effect on the proliferation of HT29 cells whereas an 11mer peptide containing an extra alanine residue was more effective than the shorter peptide variants but not as effective as RAKAKAAAAR at inhibiting cell growth (Figure 2(b)).

To determine if the presence of alanine was a specific requirement for the growth inhibitory effect, the alanine residues within RAKAKAAAAR were replaced with either valine, serine or glycine. As shown in Figure 2(c), replacement of alanine with glycine rendered the peptide ineffective except at the highest concentration, whereas the serine substitute was slightly more effective, albeit less than the alanine derivative. However, replacement of alanine residues with valine resulted in similar inhibition of growth of colon cancer cells to that observed for RAKAKAAAAR. The inhibitory effect of RAKAKAAAAR on cell growth was also examined for other cancer cell types. As shown in Figure 2(d), the peptide was equally effective at inhibiting growth of human prostate, breast and ovarian cancer cell lines in vitro.

\subsection{Peptide Uptake by Cancer Cells}

The ability of the peptide to cross the plasma membrane under serum-free conditions was assessed by means of confocal microscopy of HT29 cells exposed to KRAKAKAAAAR conjugated to FITC at its amino-terminus. As shown in Figure 3, cytoplasmic localization of peptide was observed after 24 hours in culture in contrast to the absence of uptake of FITC alone.

\subsection{Effect of Peptides on Kinase Activity}

The ability of $50 \mu \mathrm{M}$ of RSKAKNPLYR, RAKAKAAAAR, RAAKAARAAK (scrambled RAKAKAAAAR) and RVKVKVVVVR to inhibit kinase activity was determined by means of cell-free in vitro kinase assays. As shown in Figure 4, the $\beta 6$-derived peptide, RSKAKNPLYR, inhibited c-Src but not $\mathrm{PKB} \beta$ or $\mathrm{PKB} \gamma$ activity whereas the alanine-substituted peptide, RAKAKAAAAR, inhibited both c-Src and PKB $Y$ but not $\mathrm{PKB} \beta$ activity. The scrambled version of the alanine-substituted peptide, RAAKAARAAK, was ineffective at inhibiting the activity of any of the three kinases tested. In contrast, substitution of alanine by valine (RVKVKVVVVR) resulted in inhibition of the activity of all three kinases (Figure 4).

Inhibition of c-Src activity did not differ significantly between RSKAKNPLYR and RAKAKAAAAR ( $p=$ 0.132) and neither between RSKAKNPLYR and RVKVKVVVVR ( $p=0.422)$. However, RAKAKAAAAR was significantly more effective at inhibiting c-Src and PKB $r$ compared with the scrambled peptide RAAKAARAAK ( $p<0.05$ and $p<0.01$ respectively, Anova Test) as shown in Figure 4.

\section{Discussion}

Given the necessity for the NPLY motif and, in particular, the tyrosine and proline residues within that motif to render the $\beta 6$-derived peptide, RSKAKNPLYR, effective at inhibiting cancer cell proliferation, it was completely unexpected to find that substitution of all non-charged residues within this 10 -mer peptide with either alanine or valine, i.e., RAKAKAAAAR and RVKVKVVVVR, respectively, resulted in inhibition of cell proliferation to the same degree as seen for RSKAKNPLYR. This was all the more surprising because alanine and valine are 


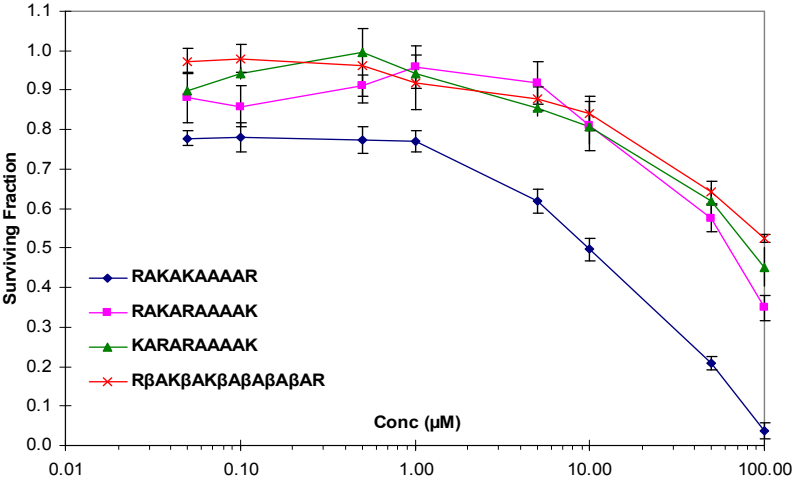

(a)

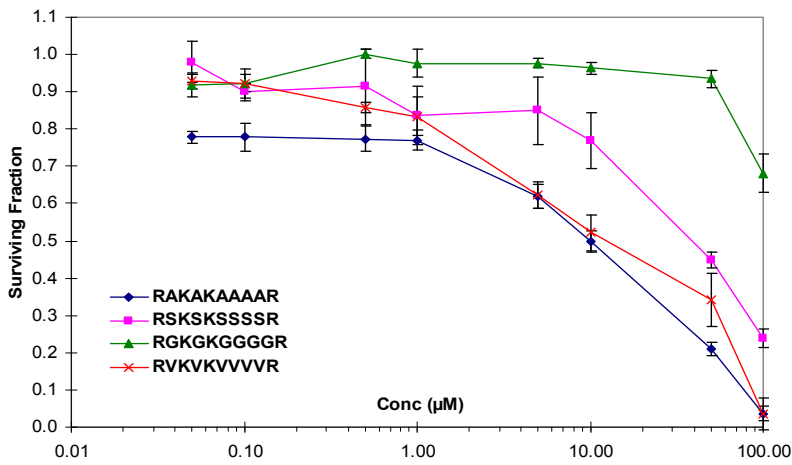

(c)

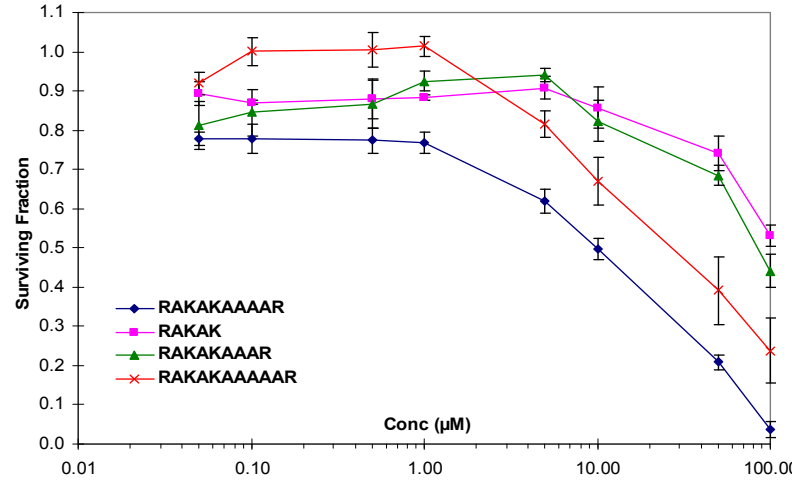

(b)

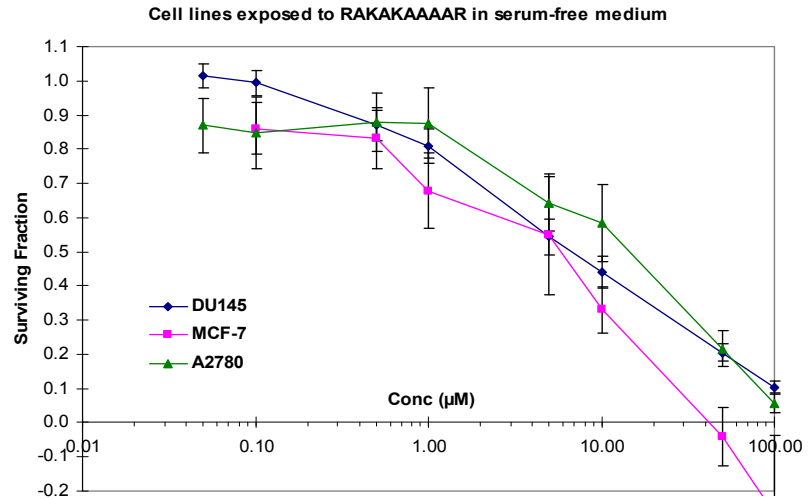

(d)

Figure 2. (a) HT29 colon cancer cells cultured under serum-free conditions and exposed to peptides for 72 hours (RA-

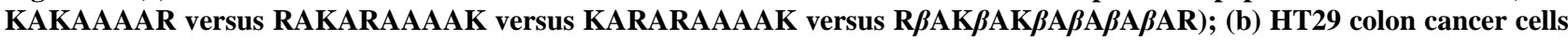
cultured under serum-free conditions and exposed to peptides for 72 hours (RAKAKAAAAR versus RAKAK versus RAKAKAAAR versus RAKAKAAAAAR); (c) HT29 colon cancer cells cultured under serum-free conditions and exposed to peptides for 72 hours (RAKAKAAAAR versus RSKSKSSSSR versus RGKGKGGGGR versus RVKVKVVVVR); (d) Prostate (DU145), breast (MCF-7) and ovarian (A2780) cancer cell lines cultured under serum-free conditions and exposed to RAKAKAAAAR for 72 hours. All data represent the means \pm SEM of the means for at least three separate experiments.

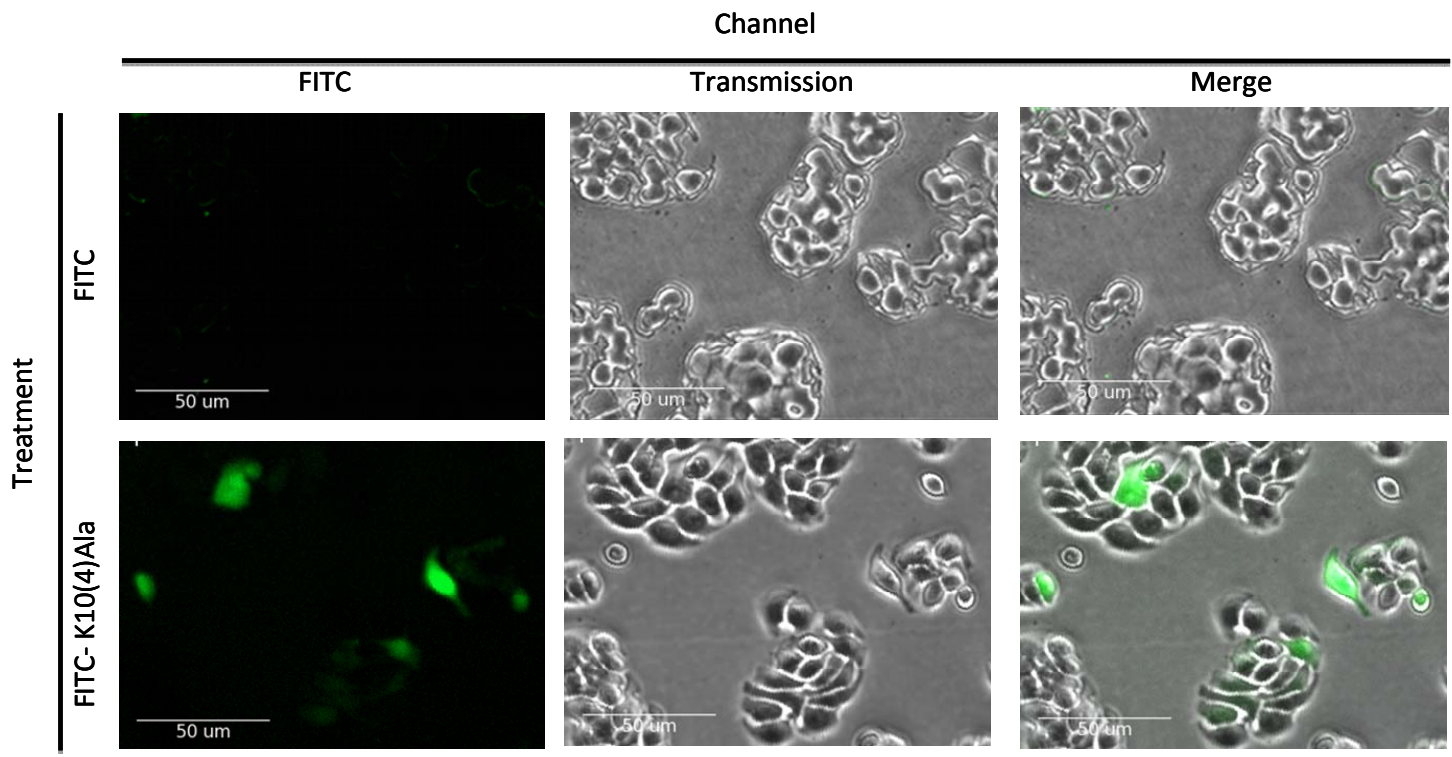

Figure 3. Uptake of FITC-conjugated KRAKAKAAAAR (designated FITC-K10(4)Ala) by HT29 cells exposed to peptide or FITC alone after 24 hours in culture under serum-free conditions. 


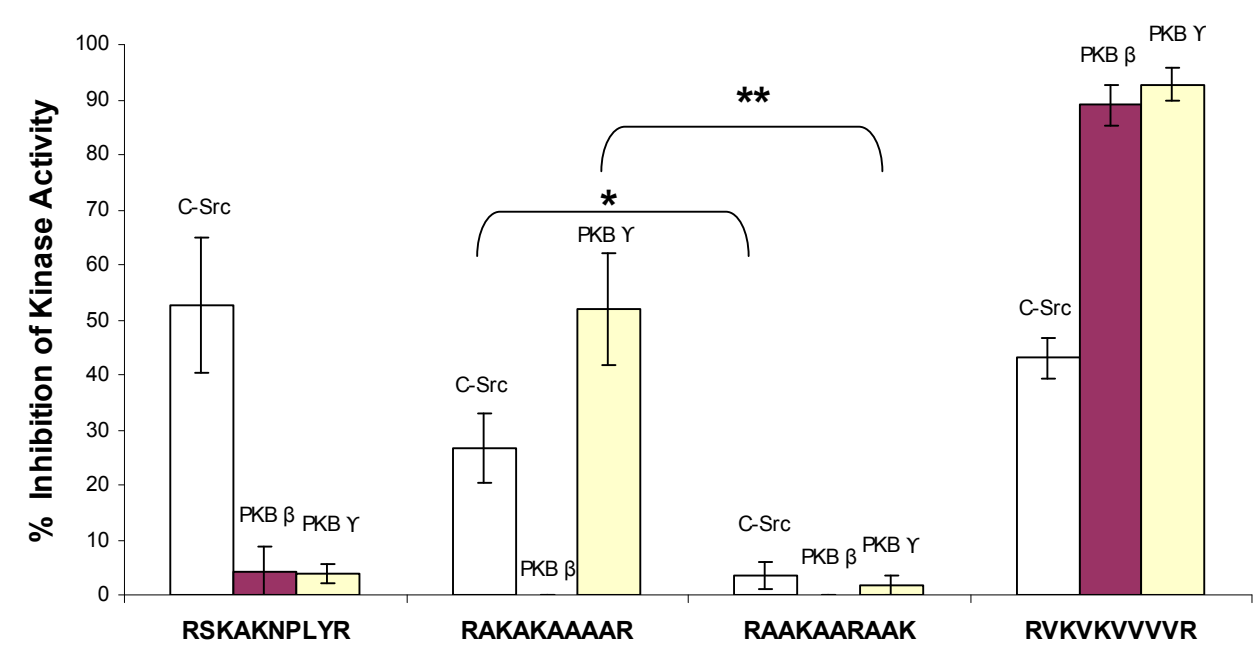

Figure 4. Percentage inhibition of kinase activity by peptides at a concentration of $50 \mu \mathrm{M}$ when tested by means of in vitro kinase assays. All data represent the means \pm SEM of the means for at least three separate experiments. c-Src-RAKAKAAAAR vs RAAKAARAAK $* \boldsymbol{p}<\mathbf{0 . 0 5}$ and PKB $r$-RAKAKAAAAR vs RAAKAARAAK $* * p<0.01$ (Anova Test).

unlikely to bind strongly to a receptor given that they are non-polar, hydrophobic amino acids with no opportunity for electrostatic interactions. In contrast, a scrambled version of RAKAKAAAAR was ineffective as shown in Figure 1(c) and indicated that the inhibitory effect of RAKAKAAAAR on cell proliferation was determined by the correct spacing and sequence of the two arginine and two lysine residues (Figure 2(a)).

Moreover, the length of RAKAKAAAAR appears to be critical. For example, while a $\beta$-alanine still retains the same tetrahedral structure as alanine, the effect of replacing alanine with $\beta$-alanine residues in the peptide RAKAKAAAAR is to lengthen the backbone of the peptide which rendered it less effective at inhibiting cancer cell growth as shown in Figure 2(a). In addition, the peptides RAKAKAAAR (9-mer) and RAKAKAAAAAR (11-mer) that contain either 3 or 5 alanine residues between the lysine and the c-terminal arginine, respectively, were both less effective at inhibiting cell growth compared with RAKAKAAAAR (10-mer) as shown in Figure 2(b), Substitution of the alanine residues within RAKAKAAAAR with either glycine, serine or valine residues rendered the peptides increasingly effective at inhibiting cell proliferation, respectively, when compared with RAKAKAAAAR as shown in Figure 2(c).

The lack of a relationship to integrin structure was further highlighted by the finding that replacement of the NPLY motif with alanine residues in the $\beta 6$-derived sequence, RSKAKNPLYR, resulted in effective inhibition of colon cancer cell proliferation whereas alanine substitution of the NPLY motif within the respective integrin cytoplasmic domains of $\beta 2, \beta 3$ and $\beta 5$ generated compounds that were relatively ineffective at inhibiting cell growth (Figure 1(d)). The novel peptide RAKAKAAAAR was also found to be similarly effective at inhibit- ing proliferation of prostate, breast and ovarian cancer cell lines in vitro (Figure 2(d)).

The PKB subfamily comprises three mammalian isoforms, $\mathrm{PKB} \alpha, \operatorname{PKB} \beta$ and $\mathrm{PKB} \gamma$ (Akt1, Akt2 and Akt3, respectively) that are frequently mutated or over-expressed in human cancer [9]. The Akt family of kinases is important not only for cell survival but also in malignant transformation [10]. Elevated Akt2 levels have been identified in 32 of 80 primary breast carcinomas [11] as well as in some ovarian and pancreatic carcinomas [12]. Akt3 has also been found to be over-expressed in breast and prostate cancers [13] and in prostate cancer basal enzymatic activity of Akt3 has been found to be constitutively elevated and represent the major Akt isoform [14]. Interestingly, inhibition of Akt3 has also recently been shown to result in reduction of VEGF resulting in less vascularised tumors in an ovarian xenograft mouse model [15]. Our findings that modifications of a non-naturally occurring decapeptide derived from the $\beta 6$ integrin cytoplasmic domain can lead to Akt kinase inhibition suggests these molecules may be developed towards new targeted therapies.

Targeting Src kinases is also relevant in cancer therapy given that Src family kinases are required for the endomembrane activation of the growth-promoting Ras-MAPK pathway and c-Src activation has been documented in upwards of $50 \%$ of tumors derived from the colon, liver, lung, breast and pancreas [16-18]. While none of the peptides described in the present study inhibits Akt1 (data not shown) RAKAKAAAAR inhibited Akt3 activity and RVKVKVVVVR inhibited the activity of both Akt2 and Akt3 as well as c-Src. However, a limitation of our study is that we have not shown that inhibition of colon cancer cell growth by these peptides is a consequence of inhibition of one or more of the kinases against 
which inhibitory activity has been identified in the in vitro kinase assays.

In summary, we have described novel anti-cancer peptides comprising only three amino acids, i.e., arginine, lysine and a non-polar, hydrophobic amino acid such as alanine or valine that inhibit Src and members of the Akt kinase family that are critical for growth of colorectal and other cancers. The role of Akt kinases as central players in regulation of cell survival and proliferation make them attractive therapeutic targets for treatment of cancer. A major challenge in cancer therapy is the ability of tumor cells to escape the growth constraints imposed on a cell when targeting a single kinase. The peptides described herein warrant further investigation as potential anticancer agents when used either alone or in combination with previously reported anti-Src kinase-inhibiting peptides.

\section{REFERENCES}

[1] M. Agrez, M. Garg, D. Dorahy and S. Ackland, "Synergistic Anti-Tumor Effect of Cisplatin when Combined with an Anti-Src Kinase Integrin-Based Peptide,” Journal of Cancer Therapy, Vol. 2, No. 3, 2011, pp. 295-301. doi:10.4236/jct.2011.23039

[2] R. O. Hynes, "Integrins: Versatility, Modulation, and Signaling in Cell Adhesion,” Cell, Vol. 69, No. 1, 1992, pp. 11-25. doi:10.1016/0092-8674(92)90115-S

[3] N. Ahmed, F. Pansino, R. Clyde, P. Murthi, M. A. Quinn, G. E. Rice, et al., "Overexpression of $\alpha \mathrm{v} \beta 6$ Integrin in Serous Epithelial Ovarian Cancer Regulates Extracellular Matrix Degradation via the Plasminiogen Activation Cascade," Carcinogenesis, Vol. 23, No. 2, 2002, pp. 237-244. doi:10.1093/carcin/23.2.237

[4] R. C. Bates, D. I. Bellovin, C. Brown, E. Maynard, B. Wu, H. Kawakatsu, et al., "Transcriptional Activation of Integrin $\beta 6$ during the Epithelial-Mesenchymal Transition Defines a Novel Prognostic Indicator of Aggressive Colon Carcinoma," Journal of Clinical Investigation, Vol. 115, No. 2, 2005, pp. 339-347

[5] N. Ahmed, J. Niu, D. J. Dorahy, X. H. Gu, S. Andrews, C. J. Meldrum, et al., "Direct Integrin $\alpha \mathrm{v} \beta 6$-ERK Binding: Implications for Tumour Growth,” Oncogene, Vol. 21, No. 9, 2002, pp. 1370-1380. doi:10.1038/sj.onc.1205286

[6] Y. Takada, X. Ye and S. Simon, "Protein family ReviewThe Integrins,” Genome Biology, Vol. 8, No. 5, 2007, p. 215.

[7] E. J. Filardo, P. C. Brooks, S. L. Deming, C. Damsky and D. A. Cheresh, "Requirement of the NPXY Motif in the Integrin Beta 3 Subunit Cytoplasmic Tail for Melanoma Cell Migration in Vitro and in Vivo," Journal of Cell Biology, Vol. 130, 1995, pp. 441-450.

doi:10.1083/jcb.130.2.441
[8] M. V. Agrez, "Methods and Agents for the Treatment of Cancer," International Patent Application, No. PCT/AU2004/001416, Publication No. WO 2005/037308.

[9] L. Bozulic, P. J. Morin, T. Hunter and B. A. Hemmings, "Meeting Report: Targeting the Kinome-20 Years Tyrosine Kinase Research in Basel,” Science STKE, Vol. 374, 2007, p. 8. doi:10.1126/stke.3742007pe8

[10] J. Q. Cheng, C. W. Lindsley, G. Z. Cheng, H. Yang and S. V. Nicosia, "The AKT/PKB Pathway: Molecular Target for Cancer Drug Discovery,” Oncogene, Vol. 24, 2005, pp. 7482-7492. doi:10.1038/sj.onc. 1209088

[11] M. Sun, J. E. Paciga, R. I. Feldman, Z. Yuan, D. Coppola, Y. Y. Lu, et al., "Phosphotidylinositol-3-OH (PI3K)AKT2, Activated in Breast Cancer, Regulates and Is Induced by Estrogen Receptor $\alpha(\mathrm{ER} \alpha)$ via Interaction between ER $\alpha$ and PI3K," Cancer Research, Vol. 61, 2001, pp. 5985-5991.

[12] J. Q. Cheng, B. Ruggeri, W. M. Klein, G. Sonoda, D. A. Altomare, D. K. Watson, et al., "Amplification of AKT2 in Human Pancreatic Cancer Cells and Inhibition of AKT2 Expression and Tumorigenicity by Antisense RNA," Proceedings of the National Academy of Science USA, Vol. 93, No. 8, 1996, pp. 3636-3641. doi:10.1073/pnas.93.8.3636

[13] K. E. Anderson, J. Coadwell, L. R. Stephens and P. T. Hawkins, "Translocation of PDK-1 to the Plasma Membrane Is Important in Allowing PDK-1 to Activate Protein Kinase B," Current Biology, Vol. 8, No. 12, 1998, pp. 684-691. doi:10.1016/S0960-9822(98)70274-X

[14] K. Nakatani, D. A. Thompson, A. Barthel, S. Hiroshi, W. Liu, R. J. Weigel, et al., "Upregulation of Akt3 in Estrogen Receptor-Deficient and Androgen Independent Prostate Cancer Cell Lines,” Journal of Biological Chemistry, Vol. 274, 1999, pp. 21528-21532. doi:10.1074/jbc.274.31.21528

[15] T. A. Liby, P. Spyropoulos, H. B. Lindner, J. Eldridge, C. Beeson, T. Hsu, et al., "Akt3 Controls Vascular Endothelial Growth Factor Secretion and Angiogenesis in Ovarian Cancer Cells,” International Journal of Cancer, Vol. 130, No. 3, 2012, pp. 532-543 doi:10.1002/ijc.26010

[16] T. G. Bivona, I. Perez De Castro, I. M. Ahearn, T. M. Grana, V. K. Chin, P. J. Lockyer, et al., "Phospholipase C Gamma Activates Ras on the Golgi Apparatus by Means of RasGRP1,” Nature, Vol. 424, No. 6949, 2003, pp. 694 698. doi:10.1038/nature01806

[17] S. C. Dehm and K. Bonham, "SRC Gene Expression in Human Cancer: The Role of Transcriptional Activation," Biochemistry and Cell Biology, Vol. 82, No. 2, 2004, pp. 263-274. doi:10.1139/o03-077

[18] J. B. Bolen, A. Veillett, A. M. Schwartz, V. DeSeau and N. Rosen, "Activation of pp60c-src Protein Kinase Activity in Human Colon Carcinoma," Proceedings of the $\mathrm{Na}$ tional Academy of Science USA, Vol. 84, No. 8, 1987, pp. 2251-2255. doi:10.1073/pnas.84.8.2251 